\title{
educação

\section{As vozes e perspetivas dos aprendentes no âmbito da investigação sobre a escrita}

\author{
José António Brandão Carvalho \\ Universidade do Minho, Portugal
}

Luís Filipe Barbeiro"

Instituto Politécnico de Leiria, Portugal

\author{
Luísa Álvares Pereira III \\ Universidade de Aveiro, Portugal
}

INÊS CARDOSOIV

York University, Canada

Eduardo Calil ${ }^{\mathrm{v}}$

Universidade Federal de Alagoas, Brasil

\begin{abstract}
A perspetiva dos alunos sobre a escrita constitui o eixo que percorre transversalmente este texto, a partir do contributo de estudos desenvolvidos em Portugal, desde a década de noventa até à atualidade. Nos primeiros três estudos considerados, essa perspetiva é captada no decurso do processo de escrita, focada na resolução de problemas por parte dos alunos, ao escreverem. As metodologias assentaram na escrita colaborativa e na integração, no processo, de estratégias facilitadoras da revisão. O segundo conjunto de estudos incide sobre as representações dos alunos em relação à escrita, considerando a pluralidade de contextos, géneros, recursos, saberes e atividades que implica. Metodologicamente, estes estudos mobilizaram textos explicitadores, questionários, entrevistas, diários, notas de campo. Os resultados mostram, em relação ao processo, uma progressão que torna salientes as limitações dos níveis de escolaridade mais baixos relativamente à reformulação e revisão. Quanto à relação com a escrita, surge em evidência o contraste entre a escrita escolar e extraescolar. As implicações remetem para a consideração didática das limitações encontradas e das potencialidades de dispositivos colaborativos e outros, facilitadores do processo, ao serviço de uma relação com a escrita que abranja a diversidade de géneros e motivações, em contextos escolares e extraescolares.
\end{abstract}

Palavras-chave: Escrita; Didática da escrita; Alunos; Investigação 


\section{IN T RO D UÇ Ã O}

A investigação sobre a aprendizagem das línguas, em geral, e sobre a aprendizagem da escrita, em particular, depara-se com uma dificuldade inerente ao facto de muitos dos aspetos envolvidos nos processos de aprendizagem e de uso da linguagem não serem diretamente observáveis, uma vez que se desenvolvem sobretudo no plano mental (Sturm, 2016). Daqui decorre que muita da investigação sobre a escrita assuma como objeto de análise o produto, ou texto, a que o processo de escrita dá origem, seja na sua versão final, seja em versões provisórias que, quando comparadas, nos permitem recolher, em maior ou menor dimensão, informações sobre o desenrolar da sua construção (FabreCols, 2002).

A análise de produtos não é, no entanto, a única forma de estudar a capacidade de escrita e o processo do seu desenvolvimento, devendo assinalar-se que o desenvolvimento tecnológico a que assistimos nas últimas décadas tem propiciado o aparecimento de novos dispositivos que permitem estudar dimensões que, de outra forma, seriam difíceis de trabalhar com alguma profundidade. Referimo-nos aos gravadores, áudio e vídeo, aos processadores de texto e a outros instrumentos de escrita que incorporam mecanismos facilitadores do registo, em tempo real, de operações de vária ordem e de muitos dos seus efeitos no texto em construção.

Entre as fontes de acesso ao conhecimento sobre a escrita, ao seu processo e ao processo da sua aprendizagem, parece-nos importante salientar as vozes e as perspetivas e representações nelas implicadas, dos sujeitos que escrevem. No caso particular deste texto, interessam-nos as vozes dos alunos, expressas no decurso de processos escriturais ou em depoimentos sobre a escrita, já que consideramos que, a partir delas, podemos eventualmente aceder a processos complexos, perceber a relação dos sujeitos com a escrita e compreender os usos que dela fazem em diferentes contextos sociais e, sobretudo, no contexto da escola, no qual, para além de objeto de aprendizagem e de veículo de comunicação, a linguagem se constitui como elemento configurador do próprio saber e instrumento implicado na sua construção.

Devemos, contudo, considerar que o acesso a tal fonte de informação nem sempre é fácil. Entre as dificuldades que podemos identificar, registem-se as de natureza metodológica, relacionadas com o acesso aos sujeitos e a adequada recolha da informação em contextos que, por vezes, dada a natureza do objeto de estudo, se configuram simultaneamente como contextos de investigação e de ensinoaprendizagem.

No trabalho de investigação sobre a escrita desenvolvido em Portugal, ao longo das últimas décadas, a perspetiva e a voz dos alunos foram, por diversas vezes, assumidas como uma das principais vertentes, constituindo o foco de projetos levados a cabo com recurso a métodos e técnicas de investigação diferenciados. O nosso objetivo neste texto é revisitar alguns desses estudos (Barbeiro, 1999, 2011; Calil \& Pereira, 2018; Cardoso, 2009; Carvalho, 1999; Pereira, Cardoso, \& Lopes, 2016), de que resultou a construção de conhecimento relevante e cientificamente sustentado sobre o desenvolvimento da escrita e sobre os processos do seu ensino e da sua aprendizagem. Numa breve descrição de cada um desses estudos, referem-se os objetivos visados, o respetivo enquadramento teórico e epistemológico, as opções metodológicas, e apresenta-se uma súmula dos resultados obtidos. Procura-se, a partir daí, evidenciar a relevância dos saberes construídos para a definição de uma Didática da Escrita 
devidamente sustentada na investigação. A concluir, interrogamo-nos sobre o impacto que o conhecimento produzido nesses estudos foi tendo nos programas escolares e noutros instrumentos reguladores, bem como nas práticas pedagógicas, e apontamos pistas para uma abordagem da escrita que motive os alunos, lhes permita adquirir a consciencialização necessária do seu próprio processo de escrita e facilite a aprendizagem desta competência.

Por razões de organização textual, enquadraremos os estudos em duas categorias: na primeira, incluiremos os estudos em que os sujeitos verbalizam o seu pensamento no decurso de um processo de escrita, incidindo essa verbalização sobre aspetos do próprio processo; na outra, integraremos aqueles em que os sujeitos, de diferentes formas, manifestam as suas perspetivas e representações sobre a escrita, sem se focarem, mesmo quando o fazem por escrito, num processo que esteja a decorrer, mas dando, afinal, elementos que nos ajudam - professores, investigadores e formadores - a configurar essas relações pessoais com a escrita.

\section{A - ESTUdOS EM QUE OS SUJEITOS} VERBALIZAM O SEU PENSAMENTO NO DECURSO DE UM PROCESSO DE ESCRITA

Nesta categoria incluem-se três estudos: Os alunos e a expressão escrita: Consciência metalinguística e expressão escrita (Barbeiro, 1999); O desenvolvimento da capacidade de escrever: Os processos de revisão do texto (Carvalho, 1999); e Reconhecimento antecipado de problemas ortográficos em escreventes novatos: Quando, como e por que acontece (Calil \& Pereira, 2018).
Os alunos e a EXPREss Ão ESCRITA: CONSCIÊNCIA METALINGUística E EXPRESSÃo ESCRITA (BARBEIRo, 1999)

Este estudo incidiu sobre o processo de escrita, designadamente sobre as operações levadas a cabo pelos sujeitos para a construção textual e sobre a fundamentação das suas decisões no âmbito desse processo. Os objetivos, focados na ligação entre o sujeito (a sua consciência metalinguística) e a expressão de escrita, consistiam em: analisar o desenrolar do processo de escrita, nomeadamente as atividades a que os sujeitos se dedicam no decurso desse processo planificação, textualização, revisão - e as relações estabelecidas entre essas atividades (Barbeiro, 1999; Flower \& Hayes, 1981); verificar em que medida e sob que modalidades a consciência metalinguística está presente no processo de escrita em alunos que frequentam diferentes níveis de escolaridade do ensino básico; determinar quais as diferenças existentes entre os diversos níveis de escolaridade considerados, procurandose, deste modo, acompanhar a presença da consciência metalinguística no processo de desenvolvimento da expressão escrita; formular propostas, a partir dos elementos encontrados, para serem desenvolvidas no âmbito do processo de ensino-aprendizagem da escrita. Para a operacionalização no estudo, considerou-se a consciência metalinguística como a manifestação de reflexão ou de controlo deliberado, incidindo sobre a linguagem (as suas unidades ou sobre as relações em que é interveniente), com vista a uma tomada de decisão e consequente operação no âmbito do processo de escrita (Barbeiro, 1999).

Em termos teóricos, este estudo enquadra os modelos processuais da atividade de escrita, nomeadamente o modelo de Flower e Hayes (1981), assumindo as componentes 
do processo como dimensões de análise (planificação, textualização, revisão); confronta a escrita e a oralidade a partir de Halliday (1985) e Vygotsky (1991a, 1991b); assume a escrita colaborativa como meio de potenciar a consideração de alternativas no processo de escrita, como meio de ativar a discussão e fundamentação das propostas para a tomada de decisão e como meio de potenciar a Zona de Desenvolvimento Próximo (ZDP) (Vygotsky, 1991a, 1991b); reconhece a importância da reflexão e da tomada de decisão consciente na escrita, com implicações ao nível da reformulação e da reescrita, e o papel da consciência metalinguística na escrita e na aprendizagem da escrita (Camps, 1994; Camps, Guash, Milian, \& Ribas, 2000; Milian, 1995; Salema, 1989).

Para acesso à dimensão da consciência metalinguística, o estudo tomou como base a escrita colaborativa, a qual obriga à negociação do texto e faz emergir aspetos relativos à consciência metalinguística, que eram objeto da investigação, nomeadamente os envolvidos na tomada de decisão, quanto a reformulação e respetiva fundamentação. O estudo envolveu uma amostra de alunos dos segundo, quarto, sexto e oitavo anos de escolaridade, organizados, de forma aleatória e no âmbito das turmas, em grupos de três elementos, apenas com a condição de os grupos serem constituídos por participantes dos dois géneros. Foram estudados oito grupos em cada ano de escolaridade, ou seja, 32 grupos, na globalidade do estudo. Os dados foram recolhidos através do registo em vídeo da tarefa de escrita em grupo. O texto produzido consistia no relato ficcionado de uma visita à cidade dos participantes, por parte de três amigos, cujos nomes eram fornecidos juntamente com outros elementos de apoio, como alguns postais ilustrados.

Os resultados evidenciam diferenças significativas quanto à complexidade do processo de escrita entre os diversos níveis de escolaridade, quer no que se refere às atividades, quer no que respeita ao tipo de operações realizadas (adição, supressão, substituição, deslocação). Relativamente às atividades inerentes às componentes do processo de escrita, verifica-se que os valores relativos à planificação apresentam diferenças estatisticamente significativas, demonstrando que os alunos, com a progressão no nível de escolaridade, planificam durante mais tempo e ocupam uma proporção maior do tempo disponível com as atividades do domínio dessa componente. No que se refere à redação, observa-se que, com o evoluir de escolaridade, os alunos gastam mais tempo a escrever, na medida em que escrevem textos mais longos. No entanto, quando se tem em conta a sua proporção em relação à duração total da tarefa, verifica-se uma evolução significativamente decrescente. Assim, enquanto a planificação, ou seja, a procura e consideração das ideias e das palavras para colocar no texto, tem um peso médio cada vez maior no processo de escrita, nos níveis de escolaridade mais elevados o ato em si de redigir vê o seu peso proporcional diminuir.

No que concerne às operações desenvolvidas, verifica-se que o processo de escrita deixa de ser progressivamente dominado pela operação de concatenação, isto é, de adição de novos elementos, passando a conjugar a vertente da formulação com a da reformulação. Analisando a proporção de cada uma das operações, observa-se que a adição de expressões linguísticas para a construção do texto (que não se encontra limitada à extremidade do fio textual) perde o lugar primordial para a operação de substituição, a qual se situa, por inteiro, no domínio da reformulação. A componente de fundamentação, ou seja, de apresentação de argumentos relativos às 
propostas para construir o texto, acompanha a vertente de reformulação e apresenta igualmente uma progressão crescente. A apresentação de uma pluralidade de alternativas, no âmbito da interação, faz emergir o discurso metalinguístico associado à decisão entre essas possibilidades. Para além do acesso a este discurso, a interação, na escrita colaborativa, revela mutuamente, entre os elementos do grupo, possibilidades para a construção do texto. Como resultado, para além das palavras presentes na versão final, muitas outras foram consideradas no processo de escrita, enriquecendo-o e chamando os participantes a decidir. A consideração de possibilidades é reforçada com a progressão na escolaridade, como mostra o facto de a ratio de palavras consideradas em relação ao número de palavras da versão final aumentar com os anos de escolaridade, correspondendo, em média, a 1,6 palavras, no segundo ano, e atingindo o valor de 3,4, no oitavo ano. A própria interação na escrita colaborativa adquire, por conseguinte, potencialidades pedagógicas, baseadas na formulação e reformulação de propostas e na sua discussão e fundamentação.

O Desenvolvimento da CAPACidade DE ESCREVER: OS PROCESSOS DE REVISÃo do TEXTO (Carvalho, 1999)

O estudo assumiu como objeto os processos de revisão do texto escrito, comparando o desempenho de alunos do quinto e do nono ano de escolaridade.

Teoricamente, este estudo inscreve-se na linha desenvolvida a partir de Flower e Hayes (1981) e de Bereiter e Scardamalia (1987), que constituíram um marco relevante em relação à investigação do processo e à apresentação de propostas para o ensino-aprendizagem. $\mathrm{O}$ modelo de Flower e Hayes (1981) concebe o ato de escrita como resultado da interação de um conjunto de processos mentais, no âmbito da qual operações de planificação, textualização e revisão vão emergindo de forma recursiva. Perspetiva a revisão como um processo que se reveste de elevada complexidade, já que implica a consideração de entidades que existem apenas no plano mental, pelo que exige, naturalmente, uma certa capacidade de abstração (Hayes, 1989; Matshuashi, 1987). Reconhece a existência de diferenças sensíveis entre a revisão feita por escreventes com maior proficiência, muito mais global, e a que é normalmente realizada por escreventes em desenvolvimento, muito mais concreta e pontual (Hayes, Flower, Schriver, Stratman, \& Carey, 1987; Yagelsky, 1995). Assume, na linha de Bereiter e Scardamalia (1987), uma estratégia de facilitação processual, que consiste na introdução de um mecanismo regulador extraordinário no processo de escrita, o qual pode passar pelo recurso a pistas, fornecidas do exterior e concebidas a partir da análise do processo de escrita e das dificuldades que lhe são inerentes, para levar o sujeito a interiorizar determinados procedimentos que normalmente não desenvolve sozinho.

A análise dos processos de revisão foi feita a partir da aplicação de uma estratégia de facilitação processual, que passava pelo recurso cíclico e sistemático a dois conjuntos de fichas, as quais tinham cores diferentes para permitir a sua diferenciação sem qualquer hierarquização. O primeiro conjunto suscitava a avaliação do texto e o segundo a sua eventual reformulação. À medida que iam escrevendo o seu texto, e sempre que usavam um ponto final, os alunos interrompiam o processo de textualização e confrontavam aquilo que tinham acabado de redigir com o conjunto de seis fichas identificado com o número $\underline{\mathrm{um}}$ :

- Acho que está tudo bem. (verde);

- Não acho que isto seja importante. (cor 
de laranja);

- Estou a repetir. (branco);

- Acho que falta referir um aspeto importante. (cor de rosa);

- Quem ler poderá achar isto pouco claro. (amarelo);

- Não é o momento mais adequado para referir isto. (azul).

A partir da seleção de uma ficha, o aluno procedia, ou não, a alterações com base nas seis fichas de reformulação, também de cores diferentes, que integravam o conjunto identificado com o número dois:

- Não altero nada. (amarelo);

- Vou retirar. (azul);

- Vou acrescentar ... (verde);

- Vou substituir a(s) palavra(s) ... por ... (cor de laranja);

- Vou reestruturar esta parte do texto. (cor de rosa);

- Vou referir isto noutra parte do texto (antes ou depois). (branco).

Como forma de monitorização do processo, pedia-se aos alunos que, em relação a cada movimento de avaliação/reformulação, assinalassem as fichas que nele tinham mobilizado. Para tornar possível o confronto da primeira versão com a versão corrigida e a análise dos movimentos realizados e sua adequação, os alunos usavam uma folha de papel com linhas contínuas e tracejadas alternadas. Nas linhas contínuas, escreviam a primeira versão; nas tracejadas, as eventuais alterações. Além disso, usavam duas esferográficas: azul, para escrever a primeira versão; vermelha, para a versão revista. Para eliminarem determinada parte do texto, colocavam-na entre parênteses. Para transporem determinada passagem, colocavam-na entre parênteses e identificavam-na com um número, após o que a reescreviam no local desejado (a vermelho, na linha tracejada), assinalando-a com o número atribuído. Na Figura 1, temos um exemplo de um texto produzido (nele, o texto resultante das alterações, escrito a vermelho nas linhas tracejadas, está em itálico).

Os alunos produziram seis textos em sessões semanais correspondentes a aulas de 50 minutos. Na primeira sessão, destinada à preparação do trabalho, o texto foi produzido no quadro com a ajuda do investigador. A

FIGURA 1. Exemplo de texto produzido pelos alunos (Carvalho, 1999) 
partir da segunda sessão, cada aluno trabalhou individualmente. Os textos produzidos tinham todos um caráter predominantemente informativo. A partir da análise dos textos, na qual as alterações efetuadas foram classificadas como aceitáveis, discutíveis e não aceitáveis, foi possível comparar o desempenho de alunos do quinto e do nono ano de escolaridade, tendo em conta não só a frequência de movimentos de revisão efetuados, mas também a natureza de revisões realizadas e sua adequação.

Numa síntese das principais conclusões destaca-se, em ambos os níveis, a dificuldade em rever o texto produzido e a restrição da maioria dos movimentos de revisão a aspetos superficiais e formais. Nota-se, no entanto, uma diferença entre os dois níveis relativamente à frequência da revisão, naturalmente maior no grupo do nono ano, bem como uma maior atenção, neste ano de final de terceiro ciclo do ensino básico, a aspetos que vão além do nível da frase e implicam a dimensão textual e o modo como a informação está estruturada. Isso é visível no recurso mais frequente a determinadas fichas, nomeadamente a branca (Vou referir isto noutra parte do texto - antes ou depois) e a cor de rosa (Vou reestruturar esta parte do texto), por parte dos alunos mais velhos.

Reconhecimento antecipado de problemas ORTOGRÁFICOS EM ESCREVENTES NOVATOS: QUANDO, como e por que acontece (Calil \& Pereira, 2018)

Os estudos de Calil $(1994,1998)$ adotam uma abordagem genética (Boré, 2010; Calil, 2008; Doquet, 2011; Fabre-Cols, 2002) e enunciativa de processos de escrita em tempo real, sob condições ecológicas da sala de aula, com base no registo audiovisual de atividades de produção textual colaborativa, em que duplas de alunos conversam e escrevem. Em cada atividade, um aluno assume o papel de ditante e o outro o de escrevente, para o registo do texto numa única folha de papel. Através deste tipo de tarefa de produção de texto, comum em propostas curriculares de base socioconstrutivista, temse acesso ao que esses alunos dizem enquanto estão a criar e a escrever. $\mathrm{O}$ procedimento de recolha de dados, de cunho etnográfico, valoriza, portanto, o diálogo in loco entre os alunos e os seus comentários espontâneos sobre diferentes dimensões textuais (gráfica, ortográfica, semântica, sintática, de pontuação, textual), reconhecidas durante o processo de produção textual. O sistema de recolha de dados durante o processo de produção textual que acabamos de descrever evoluiu, entretanto, assumindo uma natureza multimodal, com a designação de Sistema Ramos (Calil, 2015, 2017). Foi este o sistema adotado no âmbito de um estudo desenvolvido por investigadores do grupo "PROTEXTOS: Ensino e Aprendizagem da Escrita de Textos" (http://protextos.web.ua.pt/), da Universidade de Aveiro, e do Laboratório do Manuscrito Escolar (LAME), da Universidade Federal de Alagoas, a partir de 2015, o qual tornou possível a construção de uma base de dados, relativa a alunos do segundo ano do ensino básico, que tem vindo a ser objeto de estudo.

Os comentários que os alunos fazem sobre problemas ortográficos têm sido um dos aspetos analisados (Calil \& Pereira, 2018), com incidência no reconhecimento desses problemas por uma dupla de alunas recém-alfabetizadas (7 anos de idade) enquanto escreviam seis histórias inventadas. Tendo como objeto de análise o filme sincronizado pelo Sistema Ramos, os autores constataram que o reconhecimento desses problemas pode configurar três modos diferentes:

1. reconhecimento identificado através de rasuras feitas sem acompanhamento de comentários;

2. reconhecimento identificado através de 
rasuras acompanhadas por comentários;

3. reconhecimento identificado no diálogo (comentários) entre os alunos, sem que daí resultem em rasuras sobre a folha de papel.

Um ponto importante detetado pelos autores é que os dois últimos modos de reconhecimento podem ocorrer antes (reconhecimento antecipado) ou depois (reconhecimento posterior) de um determinado elemento ser grafado no texto em construção. De modo geral, o aluno que reconhece antecipadamente é o responsável por escrever, enquanto o reconhecimento posterior emerge, na maior parte das vezes, da voz do aluno que está responsável por ditar o texto.

Podemos ilustrar o primeiro modo de reconhecimento antecipado de problemas ortográficos nos exemplos abaixo, quando uma aluna está grafando a palavra “dinossauro", em dois momentos distintos.

Nos momentos transcritos, a aluna B faz dois comentários muito semelhantes antes de grafar a sílaba 'ssau'.

No turno 256 (Figura 2), ela diz “o ce-sô... ...ssaaauu...".

No turno 416 (Figura 3), ela diz: "ce-sapo...

Texto Dialogal 1: 00:30:06:08 - 00:30:23:21

Contexto: A aluna irá escrever a palavra 'dinoe-sauros':

\section{dimatsevios}

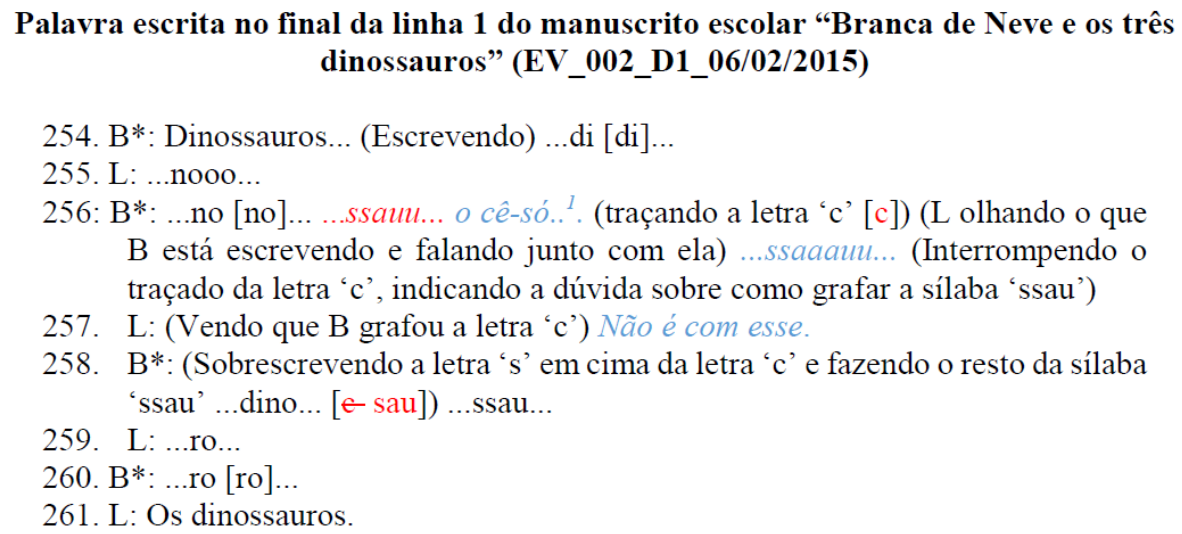

FIGURA 2. Exemplo de reconhecimento antecipado 1 (Calil \& Pereira, 2018).

Texto Dialogal 2: 00:40:05:00 - 00:40:28:19

Contexto: A aluna irá escrever a palavra 'dinosauro'

\section{dinosare}

Palavra escrita no início da linha 5 do manuscrito escolar "Branca de Neve e os três dinossauros" (EV_002_D1_06/02/2015)

414. B*: (Terminando de escrever 'a mãe') ...dinossauro... (Escrevendo 'dinossauro'.) di [di]... no [no]...

415. L: Di-no-ssau-ro.

416. B*: Di-no... 'ce'-'sapo'... ssau! (Escrevendo) Sau [sau]... ro [ro]... a mãe dinossauro... (Virando-se para L) E a mãe dinossauro... tá escrito.

FIGURA 3. Exemplo de reconhecimento antecipado 2 (Calil \& Pereira, 2018). 
ssau....

Essas enunciações sugerem que $B$ está a analisar, procurando solucionar a representação ortográfica do fonema $/ \mathrm{s} /$, cuja concorrência entre grafemas no sistema de língua portuguesa é intensa e complexa, envolvendo os grafemas $\langle\mathrm{s}\rangle,\langle\mathrm{c}\rangle,\langle\mathrm{c}\rangle,\langle\mathrm{x}\rangle$ e os dígrafos $\langle\mathrm{ss}\rangle,\langle\mathrm{sç}\rangle,\langle\mathrm{sc}\rangle$, $<\mathrm{XC}\rangle,\langle\mathrm{Xs}\rangle$.

O breve comentário posterior de $\mathrm{L}$, feito logo após ter visto a amiga desenhar o grafema <c> (turno 257), elimina a hesitação de B, fazendo-a rasurar e sobreescrever o grafema $<$ s $>$. O comentário "não é com esse", apesar de não verbalizar qual é o grafema correto, indica, por um lado, algum conhecimento metalinguístico sobre os diferentes grafemas para a representação do fonema /s/ e, por outro, mostra a atuação da aluna como revisora do manuscrito em curso. Importa observar que o papel de revisora assumido por L está comummente associado à atenção compartilhada e dirigida pelo acompanhamento visual (direção do olhar) do que está a ser escrito. Este aspeto parece ter um importante papel na escrita compartilhada por alunos desta faixa etária.

Ao destacar e decompor a sílaba e associar a primeira letra à palavra 'sapo', B recupera da sua memória de longo prazo parte da complexidade que envolve a representação do fonema $/ \mathrm{s} /$, explicitando, por sua vez, conteúdos ensinados em sala de aula. Nos meses que antecederam a realização dessa atividade de produção textual, a professora tinha enfatizado o conteúdo de ensino relativo às famílias silábicas simples. Dentre elas, as sílabas da família do 'ca' e do 'sa' foram intensamente destacadas. Pode-se observar, na enunciação da aluna $B$, a equivalência com enunciados do tipo: $\langle\mathrm{c}\rangle$ de 'casa' ou $\langle\mathrm{s}\rangle$ de 'sapato'. Essa semelhança indica o quanto a reflexão metalinguística da aluna está marcada pela voz da professora. Vale a pena observar, ainda, que no primeiro registo de 'dinossauro' é facilmente identificada uma rasura. Contudo, no segundo registo dessa palavra, não houve rasura, o que sugere que a palavra foi escrita sem que houvesse qualquer hesitação.

O outro modo de reconhecimento, como dissemos, acontece posteriormente ao registo gráfico de um elemento linguístico. Vejamos o que aconteceu durante a escrita da palavra 'ok'.

O reconhecimento do problema ortográfico sobre o modo de grafar corretamente a palavra 'ok' não deixou nenhuma rasura na folha de papel. $\mathrm{O}$ seu registo gráfico, feito por $\mathrm{B}$, indica dois aspetos interessantes relativos à aprendizagem da ortografia. O primeiro diz respeito à homofonia entre o fonema $/ \mathrm{k} /$ e a palavra gráfica 'que', recuperada por $\mathrm{B}$ à luz da memória visual que tem desta palavra. O segundo problema refere-se ao apoio na oralidade, adicionando a letra $<\mathrm{i}>$ ao final do termo.

Contudo, é no diálogo entre as alunas que temos a evidência da reflexão metalinguística que o produto textual silencia. $\mathrm{L}$, ao reconhecer a grafia de 'ok' como incorreta, recupera da sua memória a informação visual que tem deste acrónimo. Para justificar e explicar à amiga como se escreve, ela recorre a três tipos de informação: informação sobre a forma gráfica da letra, desenhando-a sobre a mesa (turno 465); informação sobre a letra inicial do nome de uma colega da turma (Katelyn); informação sobre a letra do alfabeto português europeu (capa).

Deste modo, ainda que a ortografia de 'ok' não tenha sido corrigida neste momento, temos a evidência de que mesmo alunos recémalfabetizados são capazes de efetuar reflexões metalinguísticas relacionadas com o processo de revisão textual no momento em que o texto está a ser escrito. Esse e outros estudos com análises microgenéticas e enunciativas do que os alunos dizem enquanto escrevem mostram que a escrita colaborativa a dois pode potenciar essas reflexões e atividades metalinguísticas, sugerindo a grande importância desse tipo de tarefas de produção textual no processo de aprendizagem da escrita. 
Texto-dialogal 3: 00:52:28-00:53:18

Contexto: A aluna escreveu a palavra 'Oquei'

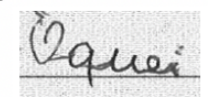

\section{Palavra escrita no meio da linha 11 do manuscrito escolar "Branca de Neve e os três dinossauros"(EV_002_D1_06/02/2015)}

457. L: (Ditando o que fala a personagem 'Branca de Neve'.) Ok. Já percebi que...

458. $\mathrm{B}^{*}$ : (Pedindo para esperar.) Pera.

459. L: (Repetindo.) Ok. Já percebi que...

460. B*: (Indo escrever.) Ó... (Interrompendo o gesto de escrever. Levando a mão ao nariz.

Sua expressão facial é de dúvida.) Pera...

461. L: (Mostrando-se um pouco irritada) Anda! Anda... (Ditando 'ok') O-k.

462. B*: (Falando enquanto escreve.) Ooo-quei [O]... (L olhando para o que B está escrevendo

e falando junto com B.) ...quei [quei]...

463. L: (Vendo que B escreveu [Oquei]. Falando com impaciência.) Ó, mãe! Tá mal!

464. B*: (Olhando para $\mathrm{L}$ e repetindo) Ooo...

465. L: (Escrevendo com o dedo a palavra 'ok' sobre a mesa e enfatizando o som / $\mathrm{k} /$ ) É 'o' ' $\mathrm{k}$ '

(Repetindo em voz alta /ok/). O-K! (Enquanto L explicava para B, a professora falava com a turma.)

466. PROF: L, L... estás a me ouvir? ( $\mathrm{L}$ e B olhando para ela.) Um bocadinho mais baixo... porque eu não estou aqui a conseguir ouvir alguns meninos. (Voltando a falar com outros alunos.).

467. B*: (B volta-se para a folha, enquanto a professora está falando) Ok! Está o 'que' (B mostrando para $\mathrm{L}$ o [Oquei] escrito na folha de papel.)

468. L: (Lendo o que está escrito.): O-que. É 'o ', "que' (Referindo-se ao "K")

469. B*: (Olhando para onde escreveu [oquei]) Oo-quei... Este é o 'que' de qual 'que'?

470. L: (Desanimada e impaciente) Ôpa, fogo!

471. B*: (Apontado para a palavra [oquei] e afirmando.) É o 'que' aqui. (Olhando para L).

472. L: (Olhando para B e explicando) Sim, mas... 'Ok' é com 'o' depois o 'que'... de Katelyn.

(B negando com a cabeça e L insistindo.) Faz o 'que' de 'Katelyn'.

473. B*: Não é não.

474. L: Pois o 'capa'! Ééé... (B negando com a cabeça) Há um 'que'... prontos!

$\mathrm{B}^{*}$ : (Lendo e repetindo o que está escrito.) Oquei. (Deixando a escrita de [Oquei] sem alteração.)

FIGURA 4. Exemplo de reconhecimento posterior (Calil \& Pereira, 2018)

\section{B - ESTUDOS EM QUE OS SUJEITOS}

MANIFESTAM AS SUAS PERSPETIVAS E

REPRESENTAÇÕES DA ESCRITA

Enquadramos, nesta categoria, três estudos: O que acontece quando escrevo (Barbeiro, 2011); A relação com a escrita extraescolar e escolar: Um estudo no ensino básico (Cardoso, 2009); A relação com a escrita ao longo da escolaridade básica (Pereira, Cardoso, \& Lopes, 2016).
O QUE ACONTECE QUANDO ESCREVO (BARBEIRO, 2011)

Nos estudos apresentados na secção precedente (Barbeiro, 1999; Carvalho, 1999; Calil \& Pereira, 2018), as perspetivas dos aprendentes encontramse associadas, de forma muito próxima e muito direta, ao desenrolar do processo de escrita de um texto em particular.

$\mathrm{O}$ estudo $O$ que acontece quando escrevo (Barbeiro, 2011) incidiu nas representações dos alunos do ensino básico sobre o processo de escrita. Foi solicitado que os alunos, numa tarefa de escrita com o tema que corresponde 
ao título do estudo, se expressassem sobre a globalidade das suas produções escritas (e não sobre a redação de um texto em concreto), para que atingissem, tanto quanto possível, um nível de generalização mais alargado na (sua) reflexão sobre a (sua) escrita. Os objetivos consistiram em analisar quais os domínios mais salientes na representação dos alunos de diferentes níveis de escolaridade do ensino básico sobre a atividade de escrita, quais as componentes ou operações que são explicitamente referidas na sua descrição do processo escritural, de uma maneira geral, e qual o sentido de progressão nessa representação ou descrição entre os diferentes níveis de escolaridade.

A integração e assunção do discurso sobre os usos da língua, na própria voz dos alunos, pode desempenhar um papel no desenvolvimento das competências em aprendizagem (Joyce, 2002), para além de revelar conceções, maneiras de fazer e dificuldades dos aprendentes em relação a essas competências, nomeadamente em relação à escrita e à realização do processo de escrita. $\mathrm{O}$ discurso metaescritural liga-se, assim, à linha que investiga o papel da metacognição na aprendizagem (Brown, Armbruster, \& Baker, 1986; Flavell, 1976, 1979; Gombert, 1993; Kaplan, 2008; Kulikowich, Mason, \& Brown, 2008). O discurso sobre a escrita e o processo de escrita pode acontecer em situações como as que mencionámos na secção anterior em relação à escrita colaborativa ou em diálogos com o professor (Graves, 1983, 1984), com o objetivo de orientar a atividade de escrita de um texto.

Em contraste com estas situações, quando o discurso é produzido por escrito, tende a assumir as características do discurso escrito: mais elaborado e refletido do que o discurso oral em interação, face a face. Foi este discurso que esteve na base do estudo realizado.

O estudo incidiu sobre um corpus de 294 textos, produzidos por alunos do primeiro ciclo do ensino básico (96 do terceiro ano de escolaridade, 110 do quarto ano) e do segundo ciclo do ensino básico ( 88 alunos do sexto ano de escolaridade).

A análise, numa vertente quantitativa, teve em conta medidas de extensão textual (número de palavras, número de unidades proposicionais) e procedeu à associação de unidades elementares dos textos produzidos (unidades de nível proposicional) a diferentes dimensões da escrita: o processo, o escrevente (e suas emoções), o texto e o leitor - dimensões baseadas em Hyland (2002), exceto no que se refere à dissociação entre o processo e o escrevente.

Os resultados relativos à extensão textual revelaram uma crescente capacidade de produção de discurso metaescritural: do terceiro para o sexto ano de escolaridade, os alunos revelam a capacidade de produzir textos mais longos quando escrevem acerca da escrita, mobilizando, consequentemente, um maior número de palavras e de unidades sintáticas, nas suas descrições e explicações.

Em relação às dimensões analisadas, o processo, o escrevente, o texto e o leitor estão presentes nos resultados, com pesos diferenciados. No que diz respeito ao processo, cerca de metade das unidades proposicionais é formulada de uma forma genérica, ou seja, os alunos adotam uma perspetiva global em relação ao processo de escrever. Pelo contrário, a outra metade é situada em relação a momentos específicos do processo. É em relação às atividades de planificação ou pré-escrita que se regista um maior crescimento de unidades que lhe estão associadas, com o avançar no nível de escolaridade, o que está de acordo com o que se observara anteriormente (Barbeiro, 1999).

A dimensão do escrevente, designadamente no que diz respeito aos sentimentos (de confiança, satisfação, receio, etc.) que vai experienciando, destaca-se em relação ao texto e ao leitor. O texto é invocado sobretudo pelas características formais que deverá apresentar, com relevo 
para os aspetos ortográficos, caligráficos e de apresentação, nos anos de escolaridade mais baixos. O leitor apresenta valores de ocorrência bastante reduzidos, o que remete para a dificuldade em ter em conta este elemento nos níveis de desenvolvimento dos sujeitos, em conformidade com o assinalado por Kellogg (2008). Quando o leitor é colocado em foco, é sobretudo para evidenciar as consequências de aspetos formais e de superfície, como os problemas associados a erros ortográficos ou de desenho descuidado das letras, para a leitura. No caso dos alunos do terceiro ano de escolaridade, o professor surge como a instância do leitor quase exclusivamente referida. Nos outros anos, começa a surgir a referência ao leitor de um modo mais indefinido, ou seja, não associada de forma tão direta ao professor, mas podendo alargar-se para além dele.

Em conclusão: as tarefas metaescriturais, como a que foi solicitada, podem revelar a relação com a escrita por parte dos alunos, no que diz respeito a aspetos atitudinais e emocionais, mas também no que diz respeito a elementos mobilizados no processo de escrita para orientar o texto a escrever ou para realizar determinadas operações nesse processo, como consulta de recursos, revisão, leitura a outras pessoas, etc. Quando colocadas em associação com um percurso de desenvolvimento, podem dar indicações ao professor para a necessidade de introduzir no ensino-aprendizagem a explicitação de aspetos a considerar, entre as estratégias e modalidades de levar à prática o processo de escrita, que, sendo pessoais e diversificadas de tarefa para tarefa, podem ser enriquecidas pelos contributos e experiências dos outros. No âmbito da turma, essa partilha e contributos podem advir das diferentes vozes, partilhadas entre os alunos, sob a orientação do professor, que pode acrescentar a sua própria voz e testemunho.
A relação com a escrita extraescolar e ESCOLAR: UM ESTUDO NO ENSINO BÁSICO (CARDOSO, 2009)

Este estudo tinha como objetivo a caracterização e compreensão da relação de alunos do ensino básico com a escrita na escola e fora da escola, quando escrevem por iniciativa própria, problematizando a responsabilidade que a escola possa ter nas representações de escrita evidenciadas pelos alunos, bem como os contributos dos saberes e competências construídos aquando de produções escritas em contexto extraescolar. Teoricamente, o trabalho inscreve-se na corrente de investigação em Didática da Escrita que, na linha de Charlot (1997, 2000) e Barré-de Miniac (2000, 2008), assenta sobre a noção de 'rapport ă' - a relação com o saber, em geral, e a relação com a escrita, em particular, tendo sido prioridade desta pesquisa aceder, precisamente, à voz dos sujeitos/alunos "para descrever e interpretar a sua relação com a escrita e, concomitantemente, procurar intervir nessa relação" (Cardoso \& Pereira, 2015, p. 83). Assume-se que o sujeito aprende mobilizando as suas crenças, preferências, saberes prévios, enfim, toda a sua pessoa (Penloup, 2006), e que, por isso, recolher elementos de como se encontra a sua relação com a escrita, com destaque para os modos de apropriação do saber escrever, pode fornecer pistas para o trabalho dos professores como agentes favorecedores da aprendizagem, em prol de uma efetiva escolarização em que o aluno se autorize a escrever, sentindo-se (Sujeito-)autor (Rocha \& Val, 2003) do seu processo de aprendizagem e dos seus textos, sem inibições relativamente à linguagem escrita (Geraldi, 2002).

Os dados foram recolhidos através de questionários, de entrevistas gravadas, de uma oficina sobre a escrita (gravações, respetivos materiais e produções dos alunos), assim 
como de notas de campo. Numa primeira fase, exploratória, através de um questionário de perguntas abertas, recolheram-se depoimentos escritos de 48 alunos do oitavo e do nono anos de escolaridade sobre a escrita escolar e extraescolar (Cardoso \& Pereira, 2007). Numa segunda fase, numa vertente extensiva, foi usado um questionário aplicado a uma amostra de 226 alunos do sexto e do oitavo anos; numa vertente intensiva, foram efetuadas duas entrevistas a cada um dos 16 alunos de uma turma do sétimo ano de escolaridade sobre a sua relação com a escrita extraescolar e escolar e sobre textos por eles produzidos (previamente entregues) em ambos os contextos, respetivamente, livre e obrigatório; paralelamente, consideraram-se discursos constantes nos diários de bordo dos jovens, instrumento que acompanhou as dez sessões da oficina, ao longo dos quatro meses da intervenção. Nestes diários individuais, os alunos, para além de escreverem durante as sessões, faziam o balanço do trabalho num registo mais introspetivo, pessoal e livre. A oficina, planificada no decurso das entrevistas, possibilitou: i) uma abordagem direta com os alunos de representações-obstáculo sobre a escrita emergentes nos seus discursos; ii) uma análise de depoimentos de escrita de outros escreventes; iii) familiarização e discussão sobre funções pessoais e sociais da escrita e sobre o processo de escrita; iv) socialização de textos extraescolares e escolares da própria turma.

Os dados recolhidos, analisados quantitativa e qualitativamente (análise de conteúdo), permitiram ficar a conhecer a relação dos alunos com a escrita, como se configurava no contexto da escola e no contexto extraescolar, nas suas várias dimensões: o investimento feito na escrita; opiniões e atitudes relacionadas com a escrita; conceções sobre a escrita e a sua aprendizagem; e modos de verbalização sobre a escrita. Confirmou-se que os alunos escrevem diversificada e abundantemente, fora dos muros da instituição escolar, quando não são obrigados a escrever. Tornou-se também possível a elaboração de um retrato das práticas de escrita escolar, tendo sido identificadas representaçõesobstáculo associadas a um paradigma redacional de ensino da escrita.

Escrever, na escola, associa-se a quatro palavras-chave: transcrição, imaginação, memorização, avaliação. Excetuando a periodicidade regular do escrever-ser avaliado, escrever-criar (imaginar) e escrever-contar (transcrição do vivido) são menos frequentes do que escrever-passar e escrever-copiar (ainda uma forma de transcrição - registo), de que os alunos se cansam com frequência, mas a que também é reconhecida utilidade, por preparar para a memorização e para a prova de conhecimentos através da escrita. Escrever-passar e escrevercopiar são a representação mais imediata do ato de escrita, relatado como um gesto motor repetitivo nas aulas, associado a cansaço físico. Ora, o predomínio de uma escrita-reprodução na escola em detrimento de uma escrita-produção ficou bem evidente, sendo o processo de escrever confundido com "atividade de escriba", ficando comprometida a experimentação da escrita como instrumento heurístico, cada vez mais necessária à medida que se progride no sistema de ensino.

O sucesso escritural (escolar) é muito mais dependente, creem os alunos, de fatores externos - como falar e ler muito e bem, saber coisas sobre o tema, o próprio professor - do que da possibilidade, ao alcance de cada um, de intervir e aperfeiçoar os seus textos (Pereira \& Cardoso, 2013). Um aspeto intrigante na relação dos alunos com a escrita é o facto de acharem a escrita escolar difícil, quando, afinal, nem experimentaram a verdadeira complexidade do processo de escrita. Talvez resida aí a explicação: os alunos não experimentam verdadeiramente a escrita, não são autores do seu escrever, na medida em que não se implicam e não aprofundam conhecimentos que fundamentem 
decisões; portanto, os alunos não sabem como dominar um texto e controlar a sua qualidade. Os alunos não se sentem à vontade a escrever na escola porque não lhes parece que esteja ao seu alcance fazer muito para escrever um texto "bom"; além do dicionário, não conhecem outros instrumentos que possam manejar para auxiliar o processo de escrita. Não é de estranhar que, a cada ato escritural escolar, se encontre frequentemente associado o sentimento de insegurança escritural, fortemente determinador da diminuição de desejo e de gosto de escrever na escola, que alguns alunos acusam.

Ficou patente também uma dualidade escritural nos sujeitos inquiridos, verificandose um contraste entre a escrita escolar alvo de desprazer, de críticas - e a escrita fora da escola - surpreendente, agradável, passatempo, sem constrangimentos. Foram traçados três ideais-tipo de relação com a escrita, considerando os dois contextos em que se desenvolve: 1) transitoriedade da escrita extraescolar e dualidade escritural acentuada; 2) imprescindibilidade da escrita extraescolar e conciliação esporádica com a escrita escolar; 3) originalidade da escrita extraescolar e conciliação mais eficaz entre diferentes contextos de escrita. No primeiro, os sujeitos não percecionam qualquer elo entre o seu mundo da escrita extraescolar - fragmentário, mas com valor afetivo - e o da escrita escolar, e não são notadas interinfluências destes dois contextos. Para os jovens que se encaixam no segundo perfil, a escrita extraescolar exprime a sua história de vida e está conectada ao seu desenvolvimento identitário, podendo ter implicações a favor de um "maior desenvolvimento" na escrita escolar, vista esta como mais correta do ponto de vista formal. No terceiro perfil, os adolescentes consideram que podem extrair das práticas escriturais extraescolares boas influências para a escrita escolar, sobretudo ao nível das ideias, das palavras (novas) e de um certo desenvolvimento na forma de produção textual, e, ao mesmo tempo, reconhecem o contributo da escola e consideram que a escrita escolar favorece uma melhor escrita extraescolar (Cardoso \& Pereira, 2015).

A relação COM A Escrita Ao longo da escolaridade básica(Pereira, Cardoso, \& Lopes, 2016)

Este estudo tinha como finalidade conhecer, a nível nacional, as práticas de escrita dos alunos em contextos escolares e extraescolares e identificar o papel das Tecnologias da Informação e da Comunicação (TIC) na relação que (re) constroem continuamente com a escrita, quer na escola quer fora da escola.

Teoricamente, e na linha do estudo anterior, este retoma a noção de 'relação com a escrita', com enfoques quer nas características, quer na sua evolução em contextos escolares e extraescolares (Penloup, 1999, 2008; Penloup \& Liénard, 2009). Coloca o foco, como outros estudos do grupo PROTEXTOS, já atrás referido, no papel e na implicação que a relação com a escrita tem na aprendizagem do processo de escrever com diferentes finalidades e no modo como uma relação favorável pode ser potenciada por dispositivos didáticos sem negligenciar a dualidade extraescolar/escolar (Cardoso \& Pereira, 2014; Cortesão, 2012; Rosário, 2010), mas promovendo mais (re)conciliações entre contextos.

O estudo envolveu uma amostra representativa nacional constituída por 1588 alunos dos quarto, sexto e nono anos do ensino básico, 831 raparigas e 757 rapazes, matriculados em escolas públicas que comportam os três ciclos do ensino básico. Foi utilizado um questionário online maioritariamente com perguntas fechadas. Os resultados indicam maior diversidade de escritos no contexto extraescolar, contrastando com focos de atuação escritural mais preponderantes 
na escola, procurando atender a prioridades de ensino-aprendizagem. Emergem, contudo, elementos de conexão entre os dois contextos, que (in)formam para uma atuação didática mais favorecedora de um percurso escritural significativo para os sujeitos (Pereira, Cardoso, \& Lopes, 2016). A última questão era aberta "Na minha opinião, preciso de três 'coisas' para escrever um bom texto" - com a intencionalidade de provocar nos alunos a liberdade total de resposta (apenas hierarquizando de 1 a 3 aquilo que dissessem), sem condicionamentos impostos por opções predeterminadas. Para a análise desta última pergunta, foram definidas categorias temáticas e subcategorias, de modo a refletirem o sentido dos indicadores.

Os resultados revelam que as imagens relativamente à escrita são flexíveis e mudam ao longo dos anos de escolaridade, numa trajetória que acompanha o próprio crescimento dos estudantes e as suas preocupações e emoções, no período da adolescência-juventude, acentuandose o contributo da escrita para a construção da identidade e expressão dos sentimentos.

Embora os textos ligados a objetivos de aprendizagem tenham para todos os alunos uma frequência expressiva em ambos os contextos, numa clara evidência de que escrever está muito associado à escola, a verdade é que as finalidades desta escrita escolar estão mais associadas a objetivos utilitários e motivações extrínsecas ao sujeito, enquanto, em contexto extraescolar, emergem motivações intrínsecas associadas a construções identitárias. Para os alunos de todos os níveis, é fundamental estar motivado para escrever, ter vontade para o fazer, ter capacidades criativas e ser proposto um "bom tema”. Apreciam um lugar calmo para escrever, necessitando apenas de lápis ou caneta e um papel. Curiosamente, não sentem necessidade de computador para a escrita dos seus textos. Revelam preocupação em fazer uma letra bonita.

Constata-se, ainda, que as palavras dos alunos de diferentes níveis do ensino básico, quando se pronunciam sobre aquilo de que necessitam para escrever, também nos possibilitam perceber como a relação com a escrita se vai moldando às caraterísticas da idade, numa linha que vai do texto ao sujeito, ou seja, num percurso que legitima, sobretudo, numa fase inicial, a necessidade de construção de um texto, com tudo o que lhe está naturalmente associado um tema, palavras e ideias -, e que, mais tarde, releva, essencialmente, a importância de um sujeito que vive a escrita com emoções e para comunicar com outros sujeitos em determinadas circunstâncias.

\section{NotaS FINAIS}

Pode-se considerar que, da investigação sobre a escrita desenvolvida ao longo das últimas décadas, em Portugal, emerge um caudal de informações muito relevantes e capaz de orientar uma Didática da Escrita (DE) realisticamente assente em princípios que decorrem das principais conclusões de tais pesquisas.

O ponto de vista dos aprendentes é, como não podia deixar de ser, de extrema relevância nessa investigação e, logicamente, também na determinação de tais princípios. Para quem quer ensinar a escrever - e não apenas solicitar a escrita dos alunos -, tanto o conhecimento do processo de escrita destes, como o conhecimento da forma como eles representam o gesto de escrever e a relação que com os escritos estabelecem são saberes essenciais e capazes de orientar tal trajeto pedagógico e didático.

As duas linhas de pesquisa que apresentamos trazem dados relevantes para a configuração de um ensino que se pretende participativo e em que as práticas textuais escolares não estejam ao serviço da (re)criação das diferenças sociais, antes ao serviço de uma escrita como meio 
de criar laços com o mundo e como meio de interpretar e organizar a realidade, começando pela própria realidade interna do sujeito.

Aceder ao pensamento dos alunos enquanto escrevem e compreender que dimensões da língua equacionam, que comentários sugerem e que (re)formulações/revisões propõem, na perspetiva de acedermos ao processo de (re)escrita e à (falta de) consciência (meta) linguística que revelam em diferentes níveis da vida escolar, tudo isto constitui, sem dúvida, informação muito relevante para se poder definir planos de ação capazes de ajudar os alunos a progredir na sua capacidade de pensar a língua e os textos.

Ao mesmo tempo, é importante perceber como os alunos "sentem" a escrita, que constitui um objeto com enorme peso na vida escolar, e também, porventura cada vez mais, na vida quotidiana de crianças e jovens, havendo entre estas duas escritas uma tensão a que a Didática da Escrita não pode ser alheia.

Nos percursos de investigação descritos neste texto, adotámos diferentes abordagens metodológicas - estudos quantitativos e qualitativos - e pudemos dispor de recursos tecnológicos que, ao longo do tempo, foram evoluindo, tornando possível a recolha de dados em contextos de maior naturalidade, o acesso a dimensões que, pela sua natureza interior, são de difícil captação, e um tratamento mais profundo e estruturado da informação. A variedade de contextos, a diversidade de técnicas e instrumentos de recolha de dados que, nestas investigações, mobilizámos oficinas de escrita, questionários, entrevistas -, bem como a análise de textos produzidos pelos alunos, forneceram um conjunto de informações de enorme relevância.

O trabalho desenvolvido representa um grande avanço da pesquisa nesta área, nomeadamente na compreensão do modo como o processo de escrita é levado a cabo por crianças e jovens de diferentes níveis de escolaridade e como, no decurso desse processo, ocorre a interligação entre consciência linguística e escrita, dimensões que continuaremos a aprofundar nos projetos em que estamos envolvidos.

Igualmente, o conhecimento das representações e crenças sobre a escrita na escola e, em contraponto, fora dela, em diferentes faixas etárias, e a perceção do modo como, em diferentes momentos da vida, emergem vivências diferenciadas com a escrita representam um importante contributo para a compreensão da relação estreita entre as perspetivas dos alunos e o desenrolar do seu processo de escrita de determinado texto.

De tudo isto, emerge um contributo relevante para a definição de uma Didática da Escrita que, por um lado, vá ao encontro das características e necessidades dos alunos em diferentes níveis de escolaridade e, por outro, seja capaz de motivar as crianças e jovens e de os envolver na atividade de escrever textos. Importa, no entanto, sublinhar que os estudos que apresentámos, focalizando o ângulo dos aprendentes, constituem apenas uma das vertentes da investigação desenvolvida. Outras dimensões da escrita, nomeadamente as implicadas nas práticas do seu ensino em contextos diversos, têm sido também objeto de investigação, com resultados igualmente pertinentes para a Didática da Escrita.

Devemos, antes de concluir, considerar ainda dois aspetos: o primeiro diz respeito ao impacto dos resultados da investigação nas práticas dos professores; o segundo contempla um conjunto de pistas, para uma abordagem da escrita consentânea com os resultados da investigação descrita.

No que concerne ao modo como a transposição dos dados da investigação para as práticas tem sido realizada, devemos reconhecer que os programas e outros 
documentos reguladores que, ao longo deste tempo, foram sendo produzidos procuraram incorporar alguns contributos da investigação desenvolvida. Parece-nos, contudo, evidente que a sua apropriação no contexto pedagógico tem sido algo incipiente e até redutora, na medida em que só o processo de escrita, nas suas componentes - planificação, textualização e revisão -, parece ter presença nos manuais e, mesmo assim, numa perspetiva de linearidade e não numa lógica de complexidade com implicação no modo como as tarefas de escrita são propostas (Carvalho, 2018; Gomes, Leal, \& Serpa, 2016).

Está, portanto, por concretizar uma efetiva implicação dos resultados da investigação sobre a escrita e a sua didática nos contextos reais de ensino e de aprendizagem. Nesse sentido, propomos, para terminar, cinco dimensões que decorrem das nossas pesquisas, aglutinadas em torno de cinco conceitos e constitutivas de uma Didática da Escrita que possa motivar os alunos para a escrita, lhes permita adquirir a consciencialização necessária do seu próprio processo de escrita e facilite a aprendizagem desta competência:

- Aumento do tempo que os alunos passam a escrever, para criar oportunidades de explicitação de opções de revisão e de reescrita, por um lado, e, por outro, de operações mais complexas, intervenientes não só na superfície textual, mas na sua estrutura profunda (em conexão com parâmetros definitórios dos géneros textuais);

- Aposta oportuna em dispositivos de colaboração - entre alunos e entre alunos e professores - que conduzam a um desenvolvimento metalinguístico adjuvante de escritas bem-sucedidas, ancoradas na consciência dos seus diferentes destinatários, em situações de comunicação com diversas finalidades;
- Monitorização de processos escriturais - rentabilização, adaptação, criação de instrumentos de facilitação processual para diversas situações escriturais, conducentes à prática de géneros escolares e não escolares, estes inerentes a diversos ramos de atividades que caiba, na escola, praticar;

- Criação de situações escolares que possibilitem uma negociação que faculte aos alunos a descoberta de sentido(s) no escrever diferentes textos - não só aqueles que a escola demanda, mas também aqueles para os quais a escola tem o objetivo de preparar, sem negligenciar, ainda, aqueles que os sujeitos querem propor, livre e criativamente, no que podemos considerar uma "aproximação ao literário";

- Negociação de critérios de avaliação, orientadores das práticas dos alunos e dos professores - os professores avaliam aquilo que ensinam e os alunos sabem o que está em causa nos percursos propostos.

Tais dimensões configurariam uma Didática da Escrita em que a progressão do aluno é promovida e aferida, pelo professor e pelo sujeito que escreve, não só em termos "técnicos", mas, sobretudo, em termos de uma evolução positiva das relações individuais com a escrita. Há muitos fatores intervenientes nesta relação. $\mathrm{E}$, se a escola não os pode alterar, pode, com certeza, contribuir para que a implicação pessoal na escrita escolar não dependa só dos apetites escriturais dos sujeitos, mas repouse numa sensibilidade crescente para o trabalho escritural, revelador de outros sentidos que os alunos maioritariamente ignoram e a que acederão progressivamente, ao longo da escolaridade. 


\section{REFERÊNCIAS}

Barbeiro, L. F. (1999). Os alunos e a expressão escrita. Lisboa: Fundação Calouste Gulbenkian.

Barbeiro, L. F. (2011). What happens when I write? Pupils' writing about writing. Reading and Writing: An Interdisciplinary Journal, 24(7), 813-834.

Barré-de Miniac, C. (2000). Le rapport à l'écriture: Aspects théoriques et didactiques. Villeneuve d'Ascq (Nord) : Presses Universitaires du Septentrion.

Barré-de Miniac, C. (2008). Le rapport à l'écriture : Une notion à valeur euristique. Diptyque, 12, 11-23.

Bereiter, C., \& Scardamalia, M. (1987). The psychology of written composition. Hillsdale, NJ: Lawrence Erlbaum Associates.

Boré, C. (2010). Modalité de la fiction dans l'écriture scolaire. Paris : Harmattan.

Brown, A., Armbruster, B., \& Baker, L. (1986). The role of metacognition in reading and studying. In J. Orasanu (Ed.), Reading comprehension: From research to practice (pp. 49-76). Hillsdale, NJ: Lawrence Erlbaum Associates, Publishers.

Calil, E. (1994). Interrelation between metaphorical and metonymical processes: Authorship and metacognitive development. In J. Wertsch, \& J. D. Ramirez (Eds.), Literacy and other forms of mediated action (Volume 2, pp. 167-171). Madrid: Fundación Infancia y Aprendizaje.

Calil, E. (1998). Autoria: A criança e a escrita de histórias inventadas. Maceió: Editora da Universidade Federal de Alagoas.

Calil, E. (2008). Escutar o invisível: Escritura \& poesia na sala. São Paulo: Funarte.

Calil, E. (2015). Escrever a dois: Estudos interconectados e comparativos de processos de escritura colaborativa de alunos brasileiros, franceses e portugueses recém-alfabetizados (InterWriting II. Projeto de Pesquisa 2016-2020). Disponível em https://www. researchgate.net/project/WRITING-IN-
DYADS-Comparative-and-interconnectedstudies-on-collaborative-writing-processesof-recently-alphabetized-BrazilianFrench-and-Portuguese-Students/ update/5a86efe04cde266d588b9c70

Calil, E. (2017). Rasura oral comentada: Definição, funcionamento e tipos em processos de escritura a dois. In C. L. Silva, A. Del Ré, \& M. Cavalcante (Orgs.), A criança na/com a linguagem: Saberes em contraponto (pp. 161-192). Porto Alegre: UFRGS.

Calil,E., \&Pereira,L.A.(2018). Reconhecimento antecipado de problemas ortográficos em escreventes novatos: Quando, como e por que acontece. Alfa, 62(1), 91-123.

Camps, A. (1994). Projectes de llengua entre la teoria I la pràctica. Articles de Didàctica de Llengua i la Literatura, 2, 7-20.

Camps, A., Guash, O., Milian, M., \& Ribas, T. (2000). Metalinguistic activity: The link between writing and learning to write. In A. Camps, \& M. Milian (Eds.), Metalinguistic activity in learning to write (pp. 103-124). Amsterdam: Amsterdam University Press.

Cardoso, I. (2009). A relação com a escrita extra-escolar e escolar. Um estudo no ensino básico (Tese de doutoramento). Universidade de Aveiro, Aveiro.

Cardoso, I., \& Pereira, L. A. (2007). A relação dos alunos com a escrita (extra-)escolar Uma experiência de investigação. Aprender, 31, 94-109.

Cardoso, I., \& Pereira, L. A. (2014). A relação de adolescentes com a escrita: Potencialidades didáticas de uma oficina sobre a escrita realizada em contexto escolar. Indagatio Didactica, 6(4), 78-95. Disponível em http://revistas.ua.pt/index.php/ID/article/ view/3024

Cardoso, I., \& Pereira, L. A. (2015). A relação dos adolescentes com a escrita extraescolar e escolar - Inclusão e exclusão por via da escrita. Trabalhos em Linguística Aplicada, 54(1), 79-107.

Carvalho, J. A. B. (1999). O ensino da escrita 
- Da teoria às práticas pedagógicas. Braga: UM - IEP - CEEP.

Carvalho, S. (2018). O ensino da escrita em manuais escolares de $5^{\circ}$ ano (Dissertação de mestrado). Universidade do Minho, Braga.

Charlot, B. (1997). Du rapport au savoir. Éléments pour une théorie. Paris: Anthropos.

Charlot, B. (2000). Da relação com o saber. Elementos para uma teoria. Porto Alegre: Artes Médicas Sul.

Cortesão, M. M. (2012). O ensino de poesia com quadro interativo. Um estudo no $1 .{ }^{\circ}$ ciclo do ensino básico (Dissertação de mestrado). Universidade de Aveiro, Aveiro.

Doquet, C. (2011). L'écriture debutante : Pratiques scripturales à l'école élémentaire. Rennes : Presses Universitaires de Rennes.

Fabre-Cols, C. (2002). Réécrire à l'école et au collège: De l'analyse des brouillons à l'écriture accompagnée. Issy-les-Moulineaux : ESF.

Flavell, J. (1976). Metacognitive aspects of problem solving. In L. B. Resnick (Ed.), The nature of intelligence (pp. 231-235). Hillsdale, NJ: Erlbaum.

Flavell, J. (1979). Metacognition and cognitive monitoring: A new area of cognitive- developmental inquiry. American Psychologist, 34, 906-911.

Flower, L., \& Hayes, J. R. (1981). A cognitive process theory of writing. College Composition and Communication, 32, 365387.

Geraldi, J. W. (2002). Culturas orais e língua escrita: Três retratos três por quatro. Educação, Sociedade \& Culturas, 18, 105121.

Gombert, J. (1993). Metacognition, metalanguage and metapragmatics. International Journal of Psychology, 28, 571580.

Gomes, M. C., Leal, S., \& Serpa, M. (2016). Abordagens à escrita no ensino básico: Do programa aos manuais escolares. Lisboa: Colibri.

Graves, D. (1983). Writing: Teachers and children at work. Exeter, NH: Heinemann.

Graves, D. (1984). A researcher learns to write: Selected articles and monographs. Exeter, NH: Heinemann.

Halliday, M. A. K. (1985). Spoken and written language. Oxford: Oxford University Press.

Hayes, J. R. (1989). Writing research: The analysis of a very complex task. In D. Klahr, \& K. Kotovsky (Eds.), Complex information processing (pp. 209-234). Hillsdale, New Jersey: Lawrence Erlbaum Associates.

Hayes, J. R., Flower, L., Schriver, K., Stratman, J., \& Carey, L. (1987). Cognitive processes in revision. In S. Rosenberg (Ed.), Advances in applied psycholinguistics. Volume II: Reading, writing and language learning (pp. 176-240). Cambridge: Cambridge University Press.

Hyland, K. (2002). Teaching and researching writing. Essex, NH: Pearson Education.

Joyce, D. (2002). On the use of metawriting to learn grammar and mechanics. The Quarterly, 24(4), 24-27.

Kaplan, A. (2008). Clarifying metacognition, self-regulation, and self-regulated learning: What's the purpose?. Educational Psychology Review, 20, 477-484.

Kellogg, R. (2008). Training writing skills: A cognitive developmental perspective. Journal of Writing Research, 1, 1-26.

Kulikowich, J., Mason, L., \& Brown, S. (2008). Evaluating fifth- and sixth-grade students' expository writing: Task development, scoring, and psychometric issues. Reading and Writing: An Interdisciplinary Journal, 21, 153-175.

Matshuashi, A. (1987). Revising the plan and altering the text. In A. Matshuashi (Ed.), Writing in real time. Modeling production processes (pp. 197-223). Norwood, NJ: Ablex Publishing Corporation.

Milian, M. (1995). El texto explicatiu: Escriure per transformar el coneixement. Articles, 5, 45-49.

Penloup, M. C. (1999). L'écriture extrascolaire des collégiens: Des constats aux perspectives 
didactiques. Paris : ESF.

Penloup, M. C. (2006). Vers une didactique de l'écriture centrée sur l'apprenant et ses pratiques. In J. Lafont-Terranova, \& D. Colin (Eds.), Didactique de l'écrit. La construction des savoirs et le sujet écrivant. Actes de la journée d'études du 13 mai 2005 (pp. 81-104). Namur : Presses Universitaires de Namur.

Penloup, M. C. (2008). Les connaissances ignorées: Approche pluridisciplinaire de ce que savent les élèves. Paris : INRP.

Penloup, M. C., \& Liénard, F. (2009). Le rapport à l'écriture, un outil pour penser la place de l'écriture électronique dans l'enseignementapprentissage de français. Actes du colloque 'Le Français dans tous ses états'. Poitiers : MSH.

Pereira, L. A., \& Cardoso, I. (2013). A sequência de ensino como dispositivo didático para a aprendizagem da escrita num contexto de formação de professores. In L. A. Pereira, \& I. Cardoso (Coords.), Reflexão sobre a escrita. O ensino de diferentes géneros de textos (pp. 33-65). Aveiro: UA Editora.

Pereira, L. A., Cardoso, I., \& Lopes, C. (2016, janeiro). A relação com a escrita ao longo da escolaridade básica. Comunicação apresentada no V SIELP/ Simpósio Internacional de Ensino de Língua Portuguesa / V FIAL - Fórum Ibero-Americano de Literacias. Braga, Universidade do Minho.

Rocha, G., \& Val, M. G. (2003). Reflexões sobre práticas escolares de produção de texto: $O$ sujeito-autor. Belo Horizonte: Autêntica.

Rosário, E. (2010). Aprendizagem da escrita através da web 2.0 - Um estudo com alunos do 3. ${ }^{\circ}$ ciclo do ensino básico (Dissertação de mestrado). Universidade de Aveiro, Aveiro.

Salema, M. H. (1989). Aprender a pensar: A composição escrita. Revista de Educação, 1(3), 59-63.

Sturm, A. (2016). Observing writing processes of struggling adult writers with collaborative writing. Journal of Writing Research, 8(2),
301-344.

Vygotsky, L. (1991a). A formação social da mente: $O$ desenvolvimento dos processos psicológicos superiores. São Paulo: Martins Fontes.

Vygotsky, L. (1991b). Pensamento e linguagem. São Paulo: Martins Fontes.

Yagelsky, R. (1995). The role of classroom context in the revision strategies of student writers. Research in the Teaching of English, 29(2), 216-238.

\begin{tabular}{|c|c|c|c|}
\hline ST UDENTS' & & I C E S & A N D \\
\hline P ERS PECTIVES & I $\mathbf{N}$ & RES E A R C H & $\mathbf{O} \mathbf{N}$ \\
\hline
\end{tabular}

\section{Abstract}

The students' perspective on writing is the axis that runs across this text, based on the contribution of several studies developed in Portugal, from the nineties to the present. In the first three studies described, this perspective is captured in the course of the writing process and focused on the problem solving strategies developed by students as they write. The methodologies were based on collaborative writing and on procedural facilitation strategies that aimed at enhancing text revision. The second set of studies focuses on the students' representations about writing, considering the plurality of contexts, genres, resources, knowledge and activities involved. Methodologically, these studies involved the analysis of students' texts about their writing as well as questionnaires, interviews, journals, field notes. The results show students' progression in the development of the writing process as they grow older and allow a better understanding of the difficulties of younger pupils in reviewing and reformulating. As far as students' relationship with writing is concerned, the contrast between school and 
out-of-school writing emerges. These findings highlight the importance of collaborative writing and procedural facilitation strategies in a didactics of writing that considers the diversity of situations, genres and motivations within and outside the school context.

KeYwORDs: Writing; Writing didactics; Students; Research

\section{LES VOIX ET LES PERSPECTIVES DES} APPRENANTS DANS LE DOMAINE DE LA RECHERCHE EN ÉCRITURE

\section{RÉSUMÉ}

Le point de vue des étudiants sur l'écriture est l'axe qui traverse ce texte, basé sur la contribution des études développées au Portugal, des années 1990 à nos jours. Dans les trois premières études examinées, cette perspective est appréhendée au cours du processus d'écriture et axée sur la résolution de problèmes par les élèves pendant qu'ils écrivent. Les méthodologies se sont fondées sur l'écriture collaborative et l'intégration, dans le processus, de stratégies qui facilitent la révision. La deuxième série d'études se concentre sur les représentations des élèves en relation avec l'écriture, considérant la pluralité des contextes, des genres, des ressources, des connaissances et des activités impliquées. Méthodologiquement, ces études ont mobilisé des textes explicatifs, des questionnaires, des entretiens, des revues, des notes de terrain. Les résultats montrent une progression par rapport au processus, qui met en évidence les limites des niveaux inférieurs d'éducation en termes de reformulation et de révision. En ce qui concerne la relation avec lécriture, le contraste entre l'école et l'écriture extrascolaire émerge. Les implications de ces résultats ont une incidence sur la prise en compte didactique des limites rencontrées et des potentialités des dispositifs collaboratifs et autres facilitateurs du processus, au service d'une relation à l'écriture qui couvre la diversité des genres et des motivations, scolaires et extrascolaires.

Mots-CLÉS : Écriture ; Enseignement de l'écriture ; Étudiants ; Recherche

${ }^{\text {I }}$ Centro de Investigação em Educação - CIEd, Instituto de Educação, Universidade do Minho, Portugal. Orcid: 0000-00030876-3101

II Escola Superior de Educação e Ciências Sociais, Instituto Politécnico de Leiria, Portugal / CELGA-ILTEC - Centro de Estudos de Linguística Geral e Aplicada - Universidade de Coimbra.

III Centro de Investigação “Didática e Tecnologia na Formação de Formadores” - CIDTFF, Universidade de Aveiro, Portugal. Orcid: 0000-0002-9742-2351

IV York University, Canada / Camões, Instituto da Cooperação e da Língua / Centro de Investigação “Didática e Tecnologia na Formação de Formadores” - CIDTFF, Universidade de Aveiro, Portugal. Orcid: 0000-0003-2687-2424

v Centro de Educação, CEDU, Laboratório do Manuscrito Escolar - LAME, Universidade Federal de Alagoas, Brasil. 